\title{
Pediatric genetics: rare is common
}

\author{
Chris Gunter ${ }^{1}$ and Wendy K. Chung ${ }^{2,3}$ \\ ${ }^{1}$ Social and Behavioral Research Branch, National Human Genome Research Institute, National Institutes of \\ Health, Bethesda, Maryland 20892, USA; ${ }^{2}$ Division of Molecular Genetics, Department of Pediatrics, \\ ${ }^{3}$ Department of Medicine, Columbia University Medical Center, New York, New York 10032, USA
}

Corresponding author: wkc15@columbia.edu

(c) 2020 Gunter and Chung This article is distributed under the terms of the Creative Commons Attribution-NonCommercial

License, which permits reuse and redistribution, except for commercial purposes, provided that the original author and source are credited.

Published by Cold Spring Harbor Laboratory Press

doi:10.1101/mcs.a005587
One of the most promising applications of genomic diagnostics has been to pediatric genetics. Early-onset and/or extreme disease manifestations are more likely to be monogenic. However, genetic heterogeneity, phenocopies, rarity, and a large fraction of disease due to de novo variants made traditional strategies like linkage analysis or association studies challenging to apply to many pediatric diseases until the era of affordable genomic analysis: first chromosome microarrays, then exome/genome sequencing, and now sometimes transcriptomics. Increasingly the questions are not if we can identify the genetic basis for disease in children, but how fast and how cost-effectively can this be done?

We are gratified to see the reports in this special issue of Cold Spring Harbor Molecular Case Studies reflecting the breadth of uses for genomic sequencing in children. Most of the case reports in this issue use molecular data to both identify mutations underlying conditions in single patients and fill out the phenotypic characteristics for rare childhood disorders. As we are all learning with each new condition identified, there is usually not a simple, genotype-phenotype relationship.

Splicing variants are increasingly identified as causes of disease. Although hundreds of cases of neonatal respiratory distress syndrome have been linked to mutations in $A B C A 3$, Oltvai et al. have the first report of a cryptic, exonic splicing variant in the gene as one of the compound heterozygous alleles seen in their patient. Koboldt et al. describe novel intronic variants in ATP7B leading to exon skipping in Wilson disease, whereas Ichikawa et al. report a novel pathogenic noncanonical splicing variant in $A K 2$ in a patient with reticular dysgenesis. In all of these cases, DNA sequencing alone was insufficient to definitely identify the variant responsible for the phenotype; additional molecular samples and analyses were required.

Additional analyses are important in cryptic cases where there is no obvious diagnosis, such as that reported by Sjaarda et al. Use of quantitative transcriptome analysis allowed them to detect a duplication on Chromosome 19 leading to a range of neurodevelopmental phenotypes in a family. Newer methodologies such as that reported by $\mathrm{Ng}$ et al. are helping to untangle complex cytogenetic cases, precisely identifying breakpoints and deleted genes in a case of $9 p-$ syndrome as well as the complex background variation throughout the genome, which may be relevant for determining the therapeutic course.

In fact, genomic data are leading us to alter taxonomy for some pediatric conditions. AbuBakr et al. reexamine contributions of mutations in the MAP3K7 gene in two overlapping disorders: cardiospondylocarpofacial syndrome (CSCFS) and frontometaphyseal dysplasia 2 (FMD2). Also in this issue, $\mathrm{Xu}$ et al. use the case study of a patient with mutations in RAB3GAP2 to expand the genotypic and phenotypic boundaries of Martsolf syndrome, suggesting that hypogonadotropic hypogonadism be established as a key part of the syndrome's description. As in other rare genetic conditions, the use of unbiased genomic 
Competing Interest Statement C.G. contributed to this article in her personal capacity. The views expressed are her own and do not necessarily represent the views of the National Institutes of Health or the United States Government. analysis to identify more patients has led us to redefine the boundaries between conditions and to appreciate the broader phenotypic spectrum of conditions than when we clinically diagnosed disorders based on cardinal clinical features.

Mosaic variant is proving to be more common, yet is more complicated to accurately access with routine depth of sequencing for most genomic analyses, and Miller et al. provide a useful summary of their experiences with exome sequencing in a pediatric tertiary-care setting. They were able to document mosaicism in five probands, representing $4.3 \%$ of the cases in whom a genetic diagnosis could be established by sequencing. Gonzalez Garcia et al. report a Cornelia de Lange syndrome case for whom blood specimen sequencing did not identify a causative variant, but saliva specimens demonstrated $\sim 60 \%$ mosaicism. Although there are many subtle genetic complexities that increase as our understanding becomes increasingly sophisticated, there are many unifying themes across rare pediatric conditions that allow us to learn common lessons that we can all apply to the understanding and care of children.

We want to thank the research community for its support of this journal that highlights the value of even single patients as we guide them on their journey to find the correct diagnosis and to use the information to improve their care. When we started this issue, none of us had ever heard of COVID-19. As we write this editorial, we can see that all of our lives have been and will be forever changed. We hope that in some cases we have learned a few lessons that will lead to improvement after COVID-19, particularly on the value of individual case studies in cataloging phenotypic complexity. 




\section{Pediatric genetics: rare is common}

Chris Gunter and Wendy K. Chung

Cold Spring Harb Mol Case Stud 2020, 6: a005587

Access the most recent version at doi: $10.1101 /$ mcs.a005587

\begin{tabular}{cl}
\hline License & $\begin{array}{l}\text { This article is distributed under the terms of the Creative Commons } \\
\text { Attribution-NonCommercial License, which permits reuse and redistribution, except } \\
\text { for commercial purposes, provided that the original author and source are credited. } \\
\text { Email Alerting } \\
\text { Service }\end{array}$ \\
$\begin{array}{l}\text { Receive free email alerts when new articles cite this article - sign up in the box at the } \\
\text { top right corner of the article or click here. }\end{array}$ \\
\hline
\end{tabular}

